\title{
Analisis Kualitatif Budaya Minahasa Dalam Perkawinan Dini Dan Implikasinya Terhadap Kehidupan Keluarga
}

\author{
Ellen Pesak ${ }^{1}$, Jon Welliam Tangka, ${ }^{2}$ Bongakaraeng $^{3}$ \\ 1. 2. 3. Politeknik Kesehatan Kemenkes Manado \\ Email : indira.bonga@gmail.com
}

\begin{abstract}
ABSTRAK
Latar Belakang: Perkembangan di era globalisasi sekarang ini, masyarakat menghadapi berbagai macam permasalahan timbulnya berbagai macam bentuk kenakalan remaja. Implikasi Pernikahan Dini bagi kehidupan keluarga diantaranya pada pengasuhan dan pendidikan anak yang tidak maksimal, sehingga terjadi perkawinan dini.

Tujuan : Menjelaskan Risiko terjadi perkawinan dini, dan dampak terjadi perkawinan dini pada kehidupan keluarga dan masyarakat pada remaja diusia 16 tahun ke bawah untuk wanita dan dibawah usia 19 tahun untuk remaja pria.

Metode : Penelitian ini adalah penelitian kualitatif yang disajikan secara deskriptif eksploratif, yaitu Informan utama adalah 8 orang, terdiri dari 4 remaja umur 11 tahun bagi remaja perempuan, dibawah 18 tahun bagi remaja laki-laki, sedangkan Informan triangulasi adalah 4 orang terdiri dari 2 orang Kepala Kelurahan, 1 Kepala Kecamatan, 1 orangtua remaja.

Hasil : Menunjukkan bahwa Perkawinan Dini dalam budaya orang Minahasa dampaknya kurang baik jika terjadi perkawinan dini ,dampak terhadap Kehidupan Keluarga dan masyarakat jika terjadi perkawinan dini remaja dan orangtua, serta masyarakat akan tidak bisa bersosialisasi hidup rukun dan damai Budaya orang Minahasa tidak mengijinkan remaja menikah dibawah umur perkawinan.

Kesimpulan : Terjadi Perkawinan dini karena kurangnya perhatian, motivasi dan pengasuhan kasih sayang orangtua terhadap remaja, masyarakat kurang memperhatikan kenakalan anak remaja saat bergaul pada masa pubertas.
\end{abstract}

Kata Kunci : Perkawinan Dini, Budaya Minahasa

\begin{abstract}
Background : Developments in the current era of globalization, people face various kinds of problems, the emergence of various forms of juvenile delinquency. The implications of early marriage for family life include child care and education which is not optimal, resulting in early marriage.

Objective : Describe the risk of early marriage, and the impact of early marriage on family and community life for adolescents aged 16 and under for women and under 19 for boys.

Method:This research is a qualitative research that is presented in a descriptive exploratory manner, namely the main informants are 8 people, consisting of 4 adolescents aged 11 years for adolescent girls, under 18 years old for boys, while the triangulation informants are 4 people consisting of 2 heads of Sub-Distric, 1 District Head, 1 teenage parent.

Result : Indicates that early marriage in the culture of the Minahasa people has a negative impact if there is early marriage, the impact on family life and society if there is early marriage between teenagers and parents, and the community will not be able to socialize in harmony and peace, Minahasa culture does not allow teenagers to marry under the age of marriage.

Conclusion : Early marriage occurs due to lack of attention, motivation and parental care for adolescents, the community pays less attention to juvenile delinquency when hanging out at puberty.
\end{abstract}

Keywords: Early Marriage, Minahasa Culture

PENDAHULUAN

Pernikahan dini diantaranya pada keluarga dan masyarakat disebabkan adanya 
kekhawatiran orang tua terhadap perilaku anak, kesiapan diri, mengurangi beban ekonomi keluarga, dan rendahnya kesadaran terhadap pentingnya pendidikan. Implikasi pernikahan dini bagi kehidupan keluarga diantaranya pada pengasuhan dan pendidikan anak yang tidak maksimal, serta pertengkaran yang seringkali berakhir pada perceraian. ${ }^{(1)}$

Masalah lain juga terjadi penyimpangan sosial pada remaja dalam bentuk, merokok, judi dan pergaulan bebas sehingga berahir dengan kehamilan sebelum pernikahan. Pacaran merupakan pintu masuk pertama terjadinya penyimpangan seksual. ${ }^{(2)}$

Pacaran bagi remaja dalam budaya orang Minahasa dianggap perbuatan tidak melanggar norma budaya masyarakat minahasa, apalagi norma Agama. Menurut budaya minahasa perkawinan yang masih umur belasan di bawah 17 tahun dianggap itu biasa, karena untuk mempercepat mendapatkan keturunan, memperbaiki sosial ekonomi keluarga dan adat budaya orang minahasa jika kawin masih muda berarti anak wanita dianggap yang paling berharga dengan kecantikannya, namun ditinjau dalam segi aturan UU Perkawinan No 1 tahun 1974 tidak diperbolehkan dan sistem reproduksi belum matang sehingga belum siap untuk bereproduksi dan mengakibatkan perdarahan jalan lahir, bayi lahir prematur, dan secara psikologi dapat mengganggu fisik dan mental anak diusia remaja.

$(3,4)$

Beberapa orang tua menikahkan anak perempuan mereka sebagai strategi untuk mendukung kelangsungan hidup ketika mengalami kesulitan ekonomi. Orang tua juga menikahkan anak perempuan mereka lebih cepat karena mereka percaya bahwa ini merupakan cara terbaik secara ekonomi bagi anak dan keluarga mereka. ${ }^{(3,5)}$

Berdasarkan uraian tersebut diatas, dukungan dan motivasi dari keluarga dan masyarakat terhadap anak remaja tentang nilai-nilai agama, etika dan moral harus ditingkatkan, Implikasi terhadap keluarga dalam kehidupan pada masyarakat keluarga akan mengalami ketidaknyamanan secara psikologi merasa terbeban akibat memikirkan anak-anak termasuk pencegahan pernikahan dini untuk mendapat perhatian yang lebih besar dari masyarakat dan pemerintah dalam hal ini adalah Kantor pencatatan Sipil di Kota Manado, Kantor Kelurahan yang ada di Kecamatan Paal 2 adalah unit terdepan dari kementrian agama dan kementerian Dalam Negeri yang melaksanakan tugas pemerintah di bidang agama dan pemerintahan daerah. Dikatakan sebagai unit terdepan, karena bersentuhan langsung dengan masyarakat di setiap kelurahan dan kecamatan bertugas melaksanakan kegiatan edukasi dan pelayanan masyarakat kepada pria dan wanita sebelum menikah atau sesudah menikah, yang juga bermanfaat bagi upaya pencegahan pernikahan yang tidak sesuai dengan ajaran agama dan hukum di Indonesia.

\section{METODE}

Penelitian ini menggunakan rancangan penelitian dengan pendekatan kualitatif yang disajikan secara deskriptif eksploratif. Pendekatan waktu pengumpulan data adalah cross sectional. Sampel penelitian ini adalah 4 remaja yang berusia dibawah 16 tahun bagi perempuan dan dibawah usia 19 tahun bagi remaja laki-laki dan 4 orang yang terdiri dari Kepala Kelurahan, Kepala kecamatan 
dan orangtua remaja. Data yang digunakan pada penelitian ini adalah data primer yaitu wawancara mendalam (Indept Interview) pada subjek penelitian dan data sekunder melalui observasi terhadap kegiatan/aktivitas sehari-hari melihat perilaku dirumah.

Pengumpulan data melalui wawancara mendalam yang dilakukan kepada informan utama yaitu 4 remaja, terdiri dari 2 remaja perempuan dan 2 remaja laki-laki berusia dibawah 16 tahun remaja perempuan, remaja laki-laki berusia dibawah 19 tahun status siswasiswi Sekolah Menengah Pertama, dan informan triangulasi yang dilakukan kepada 4 orang terdiri dari 2 Kepala Kelurahan,1 Kepala Kecamatan dan 1 Orangtua siswa.

Analisa data diolah sesuai karakteristik dengan analisis isi (content analysis) yaitu pengumpulan data, reduksi data, verifikasi disajikan dalam bentuk deskriptif, kemudian dilakukan penarikan kesimpulan.

\section{HASIL DAN PEMBAHASAN}

Hasil penelitian menunjukkan bahwa jumlah informan utama 4 remaja terdiri dari 2 remaja perempuan, 2 remaja laki-laki yang berusia dibawah 16 tahun bagi remaja perempuan dan usia dibawah 19 tahun bagi remaja laki-laki yaitu yang disebut IU1, IU2, IU3, IU4, status siswasiswi Sekolah Menengah Pertama. Untuk informan triangulasi adalah 4 orang sebagai Kepala Kelurahan, Kepala Kecamatan dan orangtua remaja yaitu yang disebut IT1, IT2,IT3,IT4, dengan usia antara 45-55 tahun, pendidikan terakhir S1 Hukum, S1 Fisip, S1 Administrasi jenis kelamin 1 orang perempuan, 3 orang laki-laki.
Risiko terjadi Perkawinan Dini pada remaja usia 16 tahun ke bawah bagi wanita dan dibawah 19 tahun bagi remaja laki-laki

Informasi yang ingin didapatkan dari wawancara mendalam tentang Risiko terjadi perkawinan dini antara lain, apa saja yang akan terjadi jika terjadi perkawinan dini, cara menghindari terjadinya perkawinan dini, apa saja hambatan dalam pergaulan di masyarakat, cara menghindari terjadinya perkawinan dini Berdasarkan wawancara mendalam dengan informan utama yaitu remaja usia 16 tahun ke bawah bagi remaja perempuan dan dibawah 19 tahun remaja laki-laki tentang risiko terjadi perkawinan dini, semuanya mengatakan bahwa jika terjadi perkawinan dini sangat berisiko karena tidak memiliki masa depan, sulit mendapat pekerjaan, terjadi perilaku kekerasan dalam rumah tangga karena usia dini dan berisiko terjadi perceraian serta kematian Ibu dan Anak dan bisa terjadi prematur, karena organ reproduksi belum matang menerima konsepsi (IU1, IU2, IU3, IU4). Hal ini dapat dilihat pada kotak 1 di bawah ini :

\section{Kotak 1}

“.....Kita jelaskan no bu... bahwa torang pe masa depan tidak terjamin dan nyanda dapa pekerjaan dan susah mendapat kerja ...." (IU1).

“.... Saya rasa rugi karena perkawinan dini terjadi kekerasan dalam rumah tangga karena pola pikir masih muda .....” (IU2).

“.... Jika terjadi perkawinan dibawah umur tantu terjadi Risiko ba cere meningkat dan Risiko terjadi kematian Ibu dan Anak meningkat..." (IU3).

“..... Kalu terjadi perkawinan pasti terjadi KDRT karena belum tau persis itu RT ...." (IU4).

“.... Perkawinan Dini sangat beRisiko karena tidak memiliki masa depan, sulit mendapat pekerjaan, terjadi perilaku kekerasan dalam 
rumah tangga karena usia dini dan beRisiko terjadi perceraian serta kematian Ibu dan Anak , terjadi prematur, organ reproduksi belum matang menerima konsepsi (IU1, IU2, IU3, IU4).

Pernyataan diatas dapat dijelaskan bahwa semua informan utama remaja usia 16 tahun ke bawah bagi remaja perempuan dan dibawah 19 tahun remaja laki-laki jika terjadi perkawinan dini tidak ada masa depan bagi anak remaja, dan akan terjadi perilaku kekerasan pertengkaran dalam rumah tangga, aborsi, bayi lahir prematur, karena sistem reproduksi belum sempurna. Dari uraian tersebut dapat di jelaskan semua informan utama maupun informan triangulasi menyampaikan bahwa sangat beRisiko jika remaja terjadi perkawinan dini diusia 16 tahun ke bawah untuk remaja perempuan dan dibawah 19 tahun untuk remaja laki-laki.

Penelitian ini dapat disimpulkan secara keseluruhan tentang Risiko terjadi perkawinan dini remaja akan mengalami kegagalan dalam kehidupan keluarganya dan di masyarakat karena putus sekolah, beRisiko membuat aborsi dan akan mengalami persalinan tidak normal yaitu Bayi lahir prematur, karena sistem reproduksi belum sempurna. Bimbingan dan motivasi terhadap remaja sangat bermakna untuk membina masa depan mereka, keterlibatan para orangtua dan tokoh agama dan masyarakat dapat berperan aktif untuk mencegah Risiko terjadi perkawinan di bawah umur. $(6,7)$

Menurut Dermanto 2017 dalam penelitiannya tentang Risiko perkawinan dini menyimpulkan bahwa perkawinan dini sering terjadi oleh karena perhatian dan motivasi dari orangtua dan guru dikelas kurang disosialisasikan pada anak remaja. $(8,9)$

Penelitian Jowari 2018 menyimpulkan bahwa sering terjadi perkawinan dibawah usia karena dipengaruhi oleh media sosial, anak ingin meniru dan mencoba dalam video film porno. $(10,11)$

\section{Dampak pada Kehidupan Keluarga jika terjadi Perkawinan Dini}

Informasi yang ingin di dapatkan dari wawancara mendalam tentang dampak terhadap kehidupan Keluarga jika terjadi perkawinan dini adalah, apa saja dampaknya jika terjadi perkawinan din, bagaimana kehidupan budaya minahasa jika terjadi perkawinan dini dalam keluarga, bagaimana tanggapan orangtua dan saudara anda, bagaimana cara menghindari jika terjadi perkawinan dini dapat dilihat dari hasil wawancara mendalam dengan informan utama, seperti pada Kotak 2 dibawah ini :

\section{Kotak 2}

“ ...Kemungkinan kita putus sekolah dan orangtua sangat kecewa karena orangtua dan kakak saya berharap kita ada cita-cita bu....." (IUI).

“...Kita rasa malu karna menjadi bahan bicara orang dan orangtua rasa kecewa putus asa....." (IU2)

“...Begini bu ada 2 kemungkinan orangtua akan tetap kita kase sekolah namun susah juga bu kita harus urus kita pe anak, .." (IU3).

“...Kita berenti sekolah dan akhirnya nyanda dapa kerja Cuma harap pa orangtua, kita so jatuhkan harga diri keluarga dan oranglain timbul rasa nyanda bagus....(IU4)

“... Keluarga orangtua sangat kecewa terjadi buah bibir antara keluarga dan akan terjadi putus sekolah tidak mendapat pekerjaan dengan demikian menjatuhkan Harga diri keluarga ...” (IU1, IU2, IU3,IU4) 
Dari uraian diatas dapat dijelaskan bahwa dampak terjadi pada kehidupan keluarga jika remaja terjadi perkawinan dini Keluarga akan kecewa terjadi kekecewaan orangtua karena putus sekolah dan harga diri dari keluarga sangat mengecewakan walaupun budaya minahasa tidak membenarkan terjadi perkawinan dini

\section{Dampak pada Masyarakat jika terjadi Perkawinan Dini.}

Informasi yang ingin di dapatkan dari wawancara mendalam tentang dampak pada masyarakat jika terjadi perkawinan dini adalah, bagaimana tanggapan orang disekitar anda jika terjadi perkawinan dini, bagaimana kehidupan budaya minahasa jika terjadi perkawinan dini pada masyarakat, bagaimana dampaknya masyarakat dan orangtua jika terjadi perkawinan dini dapat dilihat dari hasil wawancara mendalam dengan informan utama, seperti pada Kotak 3 dibawah ini :

\section{Kotak 3}

“...Jika terjadi kawin cepat masyarakat akan kaget dan heran akhirnya masyarakat nyanda percaya dan dibenci....." (IU1).

“...Masyarakat akan beranggapan reme dan selalu dicerita cerita jadi pembicaraan gosip....." (IU2)

“...Kemungkinan tingkat pengangguran akan lebih banyak apalagi remaja dibawah umur belum punya Ijasah melamar kerja, ...." (IU3).

“. Bu.....akan tersebar cerita-cerita yang nyanda enak didengar, kong masyarakat mo binci pa torang karena somo baku iko remaja lain.(IU4)

“... Pada masyarakat akan menjadi persoalan di lingkungan masyarakat dibenci dan dibicarakan secara terus menerus karena dampaknya akan terjadi pengangguran akibat belum selesai sekolah dan sudah menikah diusia muda....." (IU1, IU2, IU3,IU4)
Dalam kaitannya masyarakat tentang perkawinan dini tidak habis-habisnya persoalan secara terus menerus jika terjadi perkawinan dini, ada yang akan menjadi pengganggu akibat belum selesai sekolah dan menikah diusia muda. ${ }^{12,13}$

Pernyataan yang sama dari hasil wawancara mendalam dengan informan triangulasi Kepala Kelurahan dan orangtua murid, mengatakan bahwa perkawinan dini berdampak pada masyarakat akan mengganggu lingkungan bertetangga karena remaja belum cukup umur dan harus diberikan motivasi serta bnimbingan rohani dimasing-masing agama.

Dari uraian diatas dapat disimpulkan bahwa semua kelompok masyarakat tidak menyetujui remaja menikah diusia muda walaupun adanya budaya minahasa tidak mengijinkan remaja menikah dibawah usia perkawinan, sebaiknya menikah pada usia dewasa agar tidak mengganggu masyarakat.

\section{KESIMPULAN}

Risiko Perkawinan Dini pada remaja. Remaja dapat menjelaskan Budaya Minahasa dalam Perkawinan Dini dampaknya sangat berbahaya jika terjadi perkawinan dini banyak permasalahann yang akan ditemui. Dampak terhadap Kehidupan Keluarga jika terjadi perkawinan dini Remaja dan orangtua akan mengalami kesulitan dalam kehidupan keluarga sehingga kehidupan masa depan tidak abadi.

Dampak terhadap masyarakat jika terjadi perkawinan dini Remaja akan tidak bisa bersosialisasi dengan masyarakat dan Budaya Minahasa tidak mengijinkan remaja menikah dibawah umur perkawinan. 


\section{SARAN}

Pemerintah setempat dapat memberi motivasi pada masyarakat dengan mengagendakan pertemuan rutin untuk merespon keluhan dari masyarakat khususnya remaja dibawah usia 16 tahun bagi perempuan dan di bawah 19 tahun bagi remaja laki-laki dengan menghadirkan tokoh agama.

Keluarga dan Masyarakat dapat memberi perhatian kasih sayang bagi remaja dalam pergaulan sehari-hari dan membina hubungan baik antara orangtua dan anak serta keluarga dan masyarakat.

Rekomendasi bagi responden agar Dapat menggunakan Buku Panduan Edukasi sehingga bisa mempertahankan kepribadian dan memiliki intelektual sebagai generasi muda yang handal.

\section{DAFTAR PUSTAKA}

1. DA Triningtyas, S Muhayati (2016) Konseling Pranikah sebuah Upaya mereduksi Budaya pernikahan dini di Kecamatan Pulung Kab.Ponorogo, ejournal.unikama.ac.id

2. USF Jannah-Egalita (2016), Pernikahan dini dan Implikasinya terhadap kehidupan keluarga pada masyarakat Madura, ejournal:uin malang.ac.id

3. EY Handayani, (2016), Faktor-Faktor yang berhubungan dengan pernikahan usia dini pada remaja putri di Kecamatan Tambusai Utara Kab Rokan Hulu, simtakp.stmikubudiyah.ac.id/docjurnal/ASMAUL_HUSNA, diakses pada tanggal 12 Januari 2019.

4. AR Dwinanda, AC Wijayanti (2017), Hubungan antara Pendidikan Ibu dan Pengetahuan dengan pernikahan usia dini, Jurnal fkm.unand.ac.id

5. RD Kusumawati (2017), Hubungan tingkat pendidikan dengan Kejadian Pernikahan Dini pada wanita dibawah umur 21 tahun di Desa Keboromo Kec Tayu Kab.Pati, digilib.unisayogya.ac.id

6. F Rahman M Syahadatina R Aprillisya, (2017) Kajian Budaya remaja pelaku pernikahan dini di Kota Banjarbaru Kalimantan Selatan, medika kesehatan, journal.unhas.ac.id

7. P Hastuti, FN Aini (2017), Gambaran terjadinya pernikahan dini akibat pergaulan bebas, ejournal.poltekkes-smg.ac.id.

8. Faqih,Mansour, (2017) Analisis Faktor Pernikahan dini dan Upaya perlindungan anak http: / /www.women.it/quarta/workshops/re-figuring3/ szapuova.htm

9. L Muntamah,D Latifiani, (2019), Pernikahan dini di Indonesia Faktor dan Peran Pemerintah dalam perlindungan Hukum bagi Anak, publishing-widyagama.ac.id

10. Sartika,( 2017). Penelitian Kesehatan tentang Pengetahuan Remaja terhadap Perkawinan Dini, Skripsi Universitas Tanjungpura pontianak Fakultas Kedokteran Program Studi Keperawatan.

11. Rukmasanti, (2018) Beberapa Faktor Penyebab terjadinya perkawinan dini di Kab Kudus, Universitas Diponegoro

12. Soekamto (2018), Analisis Kejadian Perkawinan dini di Kota Surabaya, Universitas Adibuana

13. Jowari Kertaniaga (2019), Analisis Kualitatif Faktor yang berhubungan dengan Kejadian Perkawinan dini, Kota Padang.http://jurnal.fkm.unand.ac.id/index.php/jkma/article/view/90/96 Diakses pada tgl 2 Agustus 2019.

14. Kecamatan Paal 2 Kota Manado (2018) Profil Kecamatan Paal 2, http://www.kecpaal2.ac.id, diakses tanggal 22 Februari 2018.

15. Munica Rita (2019), Perkembangan Psikologi Remaja, Yogyakarta, EGC 